\title{
Provider-to-Provider Communication during Transitions of Care from Outpatient to Acute Care: A Systematic Review
}

\author{
Ngoc-Phuong Luu, MD, MHS' , Samantha Pitts, MD, MPH' , Brent Petty, MD', \\ Melinda D. Sawyer, MSN, RN, CNS-BC 3, Cheryl Dennison-Himmelfarb, PhD, $R N^{3,5}$, \\ Romsai Tony Boonyasai, MD, MPH ${ }^{1,3,4}$, and Nisa M. Maruthur, MD, $\mathrm{MHS}^{1,2,4}$ \\ 'Johns Hopkins University School of Medicine, Baltimore, MD, USA; ${ }^{2}$ Johns Hopkins University Bloomberg School of Public Health, Baltimore, MD, USA; \\ ${ }^{3}$ Johns Hopkins Armstrong Institute for Patient Safety and Quality, Baltimore, MD, USA; ${ }^{4}$ Welch Center for Prevention, Epidemiology, and Clinical \\ Research, Baltimore, MD, USA; ${ }^{5}$ Johns Hopkins University School of Nursing, Baltimore, MD, USA.
}

BACKGROUND: Most research on transitions of care has focused on the transition from acute to outpatient care. Little is known about the transition from outpatient to acute care. We conducted a systematic review of the literature on the transition from outpatient to acute care, focusing on provider-to-provider communication and its impact on quality of care.

METHODS: We searched the MEDLINE, CINAHL, Scopus, EMBASE, and Cochrane databases for English-language articles describing direct communication between outpatient providers and acute care providers around patients presenting to the emergency department or admitted to the hospital. We conducted double, independent review of titles, abstracts, and full text articles. Conflicts were resolved by consensus. Included articles were abstracted using standardized forms. We maintained search results via Refworks (ProQuest, Bethesda, MD). Risk of bias was assessed using a modified version of the Downs' and Black's tool.

RESULTS: Of 4009 citations, twenty articles evaluated direct provider-to-provider communication around the outpatient to acute care transition. Most studies were cross-sectional (65\%), conducted in the US (55\%), and studied communication between primary care and inpatient providers (62\%). Of three studies reporting on the association between communication and 30-day readmissions, none found a significant association; of these studies, only one reported a measure of association (adjusted OR for communication vs. no communication, 1.08; 95 \% CI 0.92-1.26).

DISCUSSION: The literature on provider-to-provider communication at the transition from outpatient to acute care is sparse and heterogeneous. Given the known importance of communication for other transitions of care, future studies are needed on provider-to-provider communication during this transition. Studies evaluating ideal methods for communication to reduce medical errors, utilization, and optimize patient satisfaction at this transition are especially needed.

Electronic supplementary material The online version of this article (doi:10.1007/s11606-015-3547-4) contains supplementary material, which is available to authorized users.

\section{Received April 24, 2015}

Revised September 3, 2015

Accepted October 21, 2015

Published online December 21, 2015
KEY WORDS: care transitions; continuity of care; provider-to-provider communication.

J Gen Intern Med 31(4):417-25

DOI: $10.1007 / \mathrm{s} 11606-015-3547-4$

(C) Society of General Internal Medicine 2015

\section{INTRODUCTION}

Optimizing delivery of care at stages of transitions has been a prominent focus of healthcare reform. ${ }^{1,2}$ At the same time, effective care coordination and continuity is increasingly complex as our healthcare system becomes progressively more fragmented. A major systemic element of this fragmentation began in the 1990s with the introduction of hospitalists and a separation of responsibility for inpatient care from outpatient care. ${ }^{3}$ This divorce of inpatient and outpatient care has been shown to increase the challenge of care coordination. ${ }^{4}$ Prominent among care transitions is the lack of direct communication among providers across the various health care settings. ${ }^{5}$ The delay and limited transfer of information on patients' medical histories from outpatient providers to the acute care setting can lead to omitted and/or redundant evaluations, which can result in increased length of stay and increased risk of morbidity and mortality. ${ }^{4}$ Although admission has been cited as a time of high risk for poor coordination, research to date has mainly focused on characterizing and improving the transition from the acute care setting back to the outpatient setting. ${ }^{6-10}$ The Transitions of Care Consensus Policy Statement noted that there has been "more extensive study" of the inpatient to outpatient transition, but that the outpatient to inpatient transition should also be a "clear priority."11

To address this gap in evidence, we performed a systematic review of the current literature on transition of care from the outpatient to acute care setting with the following aims: to assess what is known regarding direct provider-to-provider communication at this specific transition of care; to evaluate the factors associated with occurrence of this communication; and to evaluate whether direct provider-to-provider communication affects quality of care as measured by mortality, readmissions, length of stay, patient and provider satisfaction, as compared to no communication or indirect communication. 


\section{METHODS}

\section{Search Strategy}

We conducted a systematic review of the MEDLINE, CINAHL, Scopus, EMBASE, and Cochrane Library electronic databases from inception through 5-7 June 2014 for studies of direct communication between an outpatient provider (e.g., primary care provider, outpatient specialist, outpatient pharmacist, nursing home provider) and an acute care provider (e.g., emergency department provider, hospitalist, hospital pharmacist) at the time of transition from the outpatient to acute care. We generated search terms using database subject headings and keywords. Appendix A (see online) contains the search terms for MEDLINE. Duplicates were eliminated. We also conducted a manual search of the references of the included articles.

\section{Eligibility Criteria}

We included original articles evaluating direct communication between outpatient and acute care providers at the transition from the outpatient to acute care setting; reviews, commentaries, and meeting abstracts were excluded. We defined the term "acute care" to refer to the inpatient setting and the emergency department. We defined acute care providers as emergency department providers or inpatient providers. An outpatient provider was defined as any ambulatory-based or nursing home provider who referred patients to the acute care setting.

Direct communication could be unidirectional or bidirectional, the latter synchronous or asynchronous, and could be initiated by either party. Indirect information transfer, such as checking a patient's electronic health chart, was not included, but direct provider-to-provider messaging through electronic health record or email was included. Examples of communication included a referral letter from a primary care provider (unidirectional), provider-to-provider telephone call (synchronous, bidirectional), or a referral letter from an outpatient provider received by the acute care provider, who then sent a fax to the outpatient provider for further clarification of the communication (asynchronous, bidirectional). Though interoperable electronic health records are increasingly available to assist in the sharing of patients' healthcare information, we believe that direct provider-to-provider communication more fully fulfills the three dimensions of continuity of care (continuity in information, continuity in management, and continuity in the patient-physician relationship). ${ }^{12}$

Direct communication was compared to no communication or indirect communication between providers. Outcomes delineated a priori to be evaluated were health care utilization, length of stay, readmissions, patient satisfaction, provider satisfaction, morbidity and mortality.

We included both quantitative and qualitative studies. We excluded non-English language publications.

\section{Article Selection}

Two reviewers independently evaluated titles generated from the subject and key word searches. The title review was sensitive to avoid excluding eligible articles. Titles were included if they mentioned any handoffs or any transitions, communication between providers or discharge planning, coordination of care or organization of care. Titles were excluded if they were clearly only about the outpatient setting, clearly only about the acute care setting, or were not original articles. If one of the reviewers included the title, it was included in the next abstract review phase.

Abstracts of the included titles were reviewed independently by two reviewers, and were excluded if they met at least one of these criteria: not written in English, not about human subjects, not an original article (e.g., review, commentary, newsletter, or abstract), clearly not about transitions of care or clearly not about direct provider-to-provider communication (see Appendix B online). We did not exclude titles or abstracts that only mentioned the acute care-to-outpatient transition in the title/abstract, and reviewed the full texts of such articles to see if they did report on the outpatient-to-acute care transition.

Full texts of the included abstracts were reviewed independently by two reviewers, and were excluded if they were not an original article (e.g., review, commentary, newsletter or abstract) or did not describe direct/active communication (as defined in Eligibility Criteria) between outpatient and acute care providers (as defined in Eligibility Criteria) at the outpatient to acute care transition. The outpatient setting was defined as a home, clinic or nursing home. An outpatient provider was defined as a primary care provider including nonphysician providers (nurse practitioners, physician assistants), primary specialists (cardiologist, nephrologist, psychiatrist, etc.) or outpatient pharmacists. The acute care setting was defined as either the emergency department or hospital. An acute care provider was defined as an emergency department provider (e.g., physicians, nurse practitioners), any type of inpatient physician or mid-level provider, or inpatient pharmacist. Communication was defined as direct/active provider-toprovider communication. Direct communication could be unidirectional or bidirectional, the latter synchronous or asynchronous, and could be initiated by either party (as defined in Eligibility Criteria). Conflicts at the abstract and full text review level were resolved by consensus.

We managed citations with Refworks (ProQuest, Bethesda, $\mathrm{MD})$. Two reviewers sequentially abstracted information from the included articles on study design, population source, outpatient setting, acute care setting, follow-up period, and country using standardized forms (see online supplement). We extracted the following information on communication: frequency of the provider-to-provider communication, directionality of the communication (bidirectional, unidirectional), the method(s) of communication (e.g., telephone), the type(s) of outpatient providers involved in the communication, and the type(s) of acute care providers involved in the communication, 
and if there were specific factors associated with provider-toprovider communication (see online supplement). For outcomes, we extracted sample sizes, measures of association and confidence intervals, and whether there were any stratified analyses (see online supplement).

\section{Synthesis}

We conducted a qualitative synthesis by summarizing study characteristics and results in tables. For the available outcomes, the principal summary measure was odds ratio. We calculated odds ratios and $95 \%$ confidence intervals using Woolf's ${ }^{13}$ method when sufficient quantitative data were provided. We did not plan to conduct quantitative synthesis with meta-analysis, given the expected heterogeneity of studies.

\section{Bias Assessment}

Risk of bias was assessed independently by two reviewers using the internal validity questions as described by Downs and Black (see Appendix C online). ${ }^{14}$ We did not exclude studies on the basis of risk of bias.

\section{Registration}

We registered our systematic review protocol through PROSPERO; Registration Number: CRD42014010376.

\section{RESULTS}

\section{Description of Studies}

Of 4009 initial citations, we included 20 articles for data extraction (Fig. 1): 13 cross-sectional studies, ${ }^{15-27}$ four cohort studies, ${ }^{28-31}$ two randomized controlled trials, ${ }^{32,33}$ and one quasi-experimental study ${ }^{34}$ (Table 1). Studies were conducted in the US $(\mathrm{n}=11),{ }^{15-21,24,28,29,34}$ Australia $(\mathrm{n}=6),{ }^{22,25,30-33}$ and United Kingdom $(n=3){ }^{23,26,27}$ Most studies evaluated the transition from outpatient clinic to hospital admission $(n=9) .{ }^{16,19,21-23,25,27,28,32}$ Other described transitions included nursing home to the emergency department (four studies), ${ }^{17,18,20,34}$ clinic to the emergency department (four studies), ${ }^{26,30,31,33}$ and three from an unspecified site to hospital admission. $15,24,29$

Overall, the majority of the acute care settings involved are individual hospitals. ${ }^{15,16,19,21-25,27,28,30,32,33}$ Three studies noted academic centers as the acute care setting ${ }^{15,16,19}$ and four other studies described a "district hospital's" involvement. ${ }^{23,27,30,33}$ None of the studies reviewed clearly stated that the study involved integrated health systems (see Table 1).

\section{Provider-to-Provider Communication Quantitative Results}

Fourteen of the $20(70 \%)$ articles ${ }^{15,16,21-24,27-34}$ reported quantitative results on the occurrence of provider-to-provider communication (Table 2).

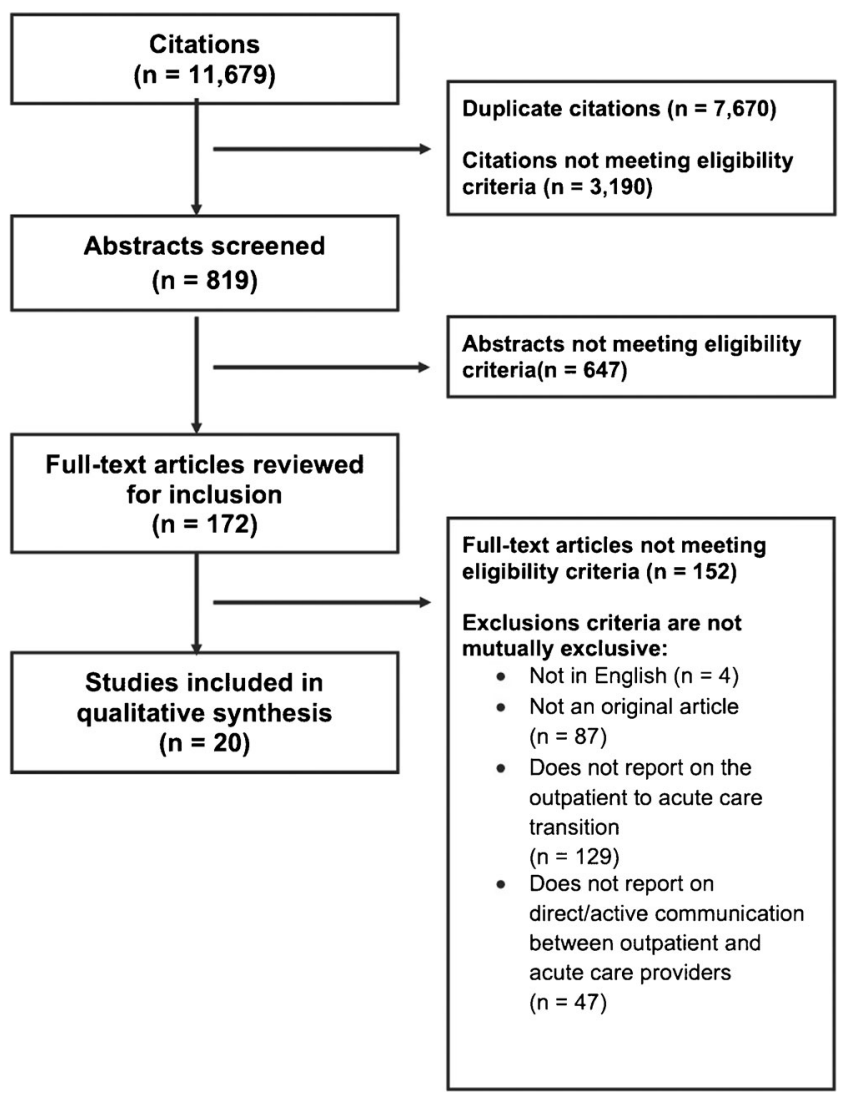

Figure 1 Flow diagram of article selection.

Frequency of Communication. There was substantial heterogeneity in how each study defined direct communication between providers. Out of the 14 studies with quantitative data, seven reported numerical frequencies of direct communication. The two studies reporting the highest direct communication rates were ones that used telephone contact as the mode of communication: 1) between a hospitalist to a primary care provider $(69 \%)^{28}$; and 2 ) a medical resident telephoning a primary care provider $(70.5$ $\%{ }^{24}$ Direct communication via referral letters was only moderately successful, either via electronic referrals $(21 \%)^{34}$ or written referrals from the general practitioner taken to the emergency department $(19.7 \%) .{ }^{31}$ One study ${ }^{21}$ utilized medical record review to confirm if an inpatient provider had documented whether they notified the outpatient provider, and that had the lowest rate of direct communication; only $9.5 \%$ of the medical records reviewed documented communication between an inpatient team and primary care provider. Finally, two studies ${ }^{15,29}$ noted the direct communication frequency, but it was unclear via what mode(s) communication occurred.

Types of Providers Involved in the Communication. Thirteen of 14 articles $(93 \%)^{15,16,21-23,27-33}$ identified primary care providers/general practitioners as the predominant outpatient provider involved in the communication (see Table 2). Among those 13 studies, eight described communication with an 
Table 1 Characteristics of Included Studies $(\mathbf{n}=\mathbf{2 0})$

\begin{tabular}{|c|c|c|c|}
\hline Author, year & Study Design & Country & Population and Setting \\
\hline Oduyebo 2013 & Cross-sectional & US & $\begin{array}{l}\text { Discharging providers on inpatient medical services at a single } \\
\text { academic hospital for patients with a first admission from } \\
\text { September } 2010 \text { to December } 2011 \text { ( } \mathrm{n}=6635 \text { patients })\end{array}$ \\
\hline
\end{tabular}

Hennrikus 2012 Cross-sectional US

Terrell 2011

Cross-sectional

US

Gillespie 2010

Cross-sectional

US

Harlan 2009

Cross-sectional

US

Terrell 2006

Cross-sectional

US

Hruby 2002

Stowasser $2002 b$

Mead 1999

Ways 1995

Hadfield 1994

Balla 1994

Victor 1993

McMillan 2013

Bell 2008

Ramrakha 2001

Cohort

Australia

Montalto 1994

Cohort

Australia

Stowasser 2002a

Randomized controlled trial

Australia

Harris 2001

Zamora 2012
Randomized controlled trial

Australia
Primary care providers $(n=34)$ of patients admitted to the medicine service at a single academic hospital from July 2009 to March 2010

Focus group interviews $(\mathrm{n}=2)$ of nursing home administrators, nursing home and emergency department physicians, nursing home and emergency department nurses, paramedics and emergency medical technicians ( $\mathrm{n}=18$ participants)*

Physicians, nurse practitioners, physician assistants, and nurses $(n=155)$ who practice in emergency department or nursing home settings affiliated with an academic center were surveyed in September 2008

Pediatric hospitalists and primary care providers $(n=22)$ who shared patients at an academic center in 2004

Focus group interviews $(\mathrm{n}=7)$ of nursing home administrators, nursing home and emergency department physicians, nursing home and emergency department nurses, paramedics, emergency medical technicians, and social workers $(\mathrm{n}=60)$. Interviews conducted from May to August 2005

Patients hospitalized on a general internal medicine service $(n=74)$ from July to August 1998

Ten resident medical officers in a general medicine ward*

General practitioners for 300 consecutive patients who were admitted to a district general hospital*

Primary care providers $(n=74)$ who had patients admitted to a medicine ward from April to May 1994

General practitioners $(\mathrm{n}=77)$ who were part of the Family Services Health Authority in Salford, United Kingdom in 1991

General practitioners of 30 patients who were admitted to a medical ward and discharged were interviewed*

Providers and staff $(n=292)$ who worked and/or were referred to an inner-London district health authority*

Hospitalists and family physicians with mutual patients admitted from January to July 2009 at a single hospital (120 admissions included)

Random sampling of primary care providers who were contacted $(n=1,213)$ if their patient had recently been discharged from one of six academic centers from July 2001 to June 2003

Patients presenting to Liverpool Hospital's emergency department in southwest Australia $(n=998)$ who were sent by their general practitioners from June to September 1997

Patients $(n=842)$ referred to the emergency department from their general practitioner between 17 August and 14 September 1992

Patients recruited from pre-admission clinic and acute ward service $(n=481)$ from 1996 to 2000

General practitioners $(\mathrm{n}=155)$ who referred patients to Liverpool Hospital from June to October 1998

Emergency room physicians $(n=26)$ who received web-based referrals from nursing homes regarding patient transfers*

*Unclear date of study for these studies

inpatient medical provider (62\%), ${ }^{15,16,21-24,27,28}$ three reported communication with the emergency department provider (23
$\%),{ }^{30,31,33}$ one with an inpatient pharmacist $(8 \%),{ }^{32}$ and one study did not specify the acute care provider $(8 \%){ }^{29}$ 
Table 2 Provider-to-Provider Communication: Direction, Mode and Frequency ( $n=14)$

\begin{tabular}{|c|c|c|c|c|c|}
\hline Author, Year & $\begin{array}{l}\text { Acute Care } \\
\text { Provider(s) } \\
\text { Involved in } \\
\text { Communication }\end{array}$ & $\begin{array}{l}\text { Outpatient } \\
\text { Provider(s) } \\
\text { Involved in } \\
\text { Communication }\end{array}$ & $\begin{array}{l}\text { Direction of } \\
\text { Communication }\end{array}$ & $\begin{array}{l}\text { Mode(s) of } \\
\text { Communication }\end{array}$ & $\begin{array}{l}\text { Frequency of } \\
\text { Communication }\end{array}$ \\
\hline McMillan 2013 & Hospitalist & $\begin{array}{c}\text { Primary care } \\
\text { provider }\end{array}$ & $\begin{array}{l}\text { Unidirectional } \\
\text { Hospitalist } \rightarrow \mathrm{PCP}^{\mathrm{i}}\end{array}$ & $\begin{array}{l}\text { PCPs notified of admission } \\
\text { by receipt of admission } \\
\text { summary (some telephone } \\
\text { contact from hospitalist) }\end{array}$ & $\begin{array}{l}\text { Primary care providers } \\
\text { notified of admission } \\
69 \% \text { of the time }\end{array}$ \\
\hline Oduyebo 2013 & Hospitalist & $\begin{array}{l}\text { Primary care } \\
\text { provider }\end{array}$ & Not reported & Not reported & $\begin{array}{l}\text { Of } 6635 \text { admitted patients } \\
\text { during September } \\
2010 \text { to December } \\
2011, \text { "successful" } \\
\text { communication } \\
\text { with PCP recorded } \\
\text { for } 2438(36.7 \%)\end{array}$ \\
\hline Hennrikus 2012 & Hospitalist & $\begin{array}{l}\text { Primary care } \\
\text { provider }\end{array}$ & $\begin{array}{l}\text { Asynchronous, } \\
\text { bidirectional } \\
\text { Hospitalist } \leftrightarrow \text { PCP }\end{array}$ & $\begin{array}{l}\text { Hospitalist sent template } \\
\text { form with admission } \\
\text { information to PCP; } \\
\text { form returned by PCP } \\
\text { by fax or telephone }\end{array}$ & Not Reported \\
\hline Zamora 2012 & ED staff & $\begin{array}{l}\text { Nursing home } \\
\text { staff }\end{array}$ & $\begin{array}{l}\text { Asynchronous, } \\
\text { bidirectional } \\
\text { Nursing home staff } \\
\leftrightarrow \text { ED staff }\end{array}$ & $\begin{array}{l}\text { Nursing home staff filed } \\
\text { referral electronically; at } \\
\text { ED discharge, ED staff } \\
\text { filed discharge note } \\
\text { electronically }\end{array}$ & $\begin{array}{l}\text { Of } 313 \text { referrals to the } \\
\text { ED from a single } \\
\text { nursing home, } 66 \\
(21 \%) \text { were } \\
\text { accompanied by an } \\
\text { electronic referral note } \\
\text { completed by nursing } \\
\text { home staff }\end{array}$ \\
\hline Bell 2008 & Not reported & $\begin{array}{l}\text { Primary care } \\
\text { provider }\end{array}$ & Not reported & Not reported & $\begin{array}{l}\text { Of } 834 \text { PCPs aware } \\
\text { of their patient's } \\
\text { hospitalization, } 194 \\
(23 \%) \text { had direct } \\
\text { contact with the } \\
\text { general internal } \\
\text { medicine service }\end{array}$ \\
\hline Hruby 2002 & $\begin{array}{l}\text { Only stated } \\
\text { inpatient } \\
\text { provider, } \\
\text { unknown } \\
\text { type }\end{array}$ & $\begin{array}{l}\text { Primary care } \\
\text { provider }\end{array}$ & Not reported & $\begin{array}{l}\text { Medical record review to } \\
\text { see if inpatient provider } \\
\text { had documented whether } \\
\text { they notified the outpatient } \\
\text { provider, specific mode } \\
\text { unclear }\end{array}$ & $\begin{array}{l}\text { Communication between } \\
\text { inpatient team and PCP } \\
\text { documented for seven } \\
(9.5 \%) \text { of } 74 \text { medical } \\
\text { records }\end{array}$ \\
\hline Stowasser $2002 \mathrm{a}$ & $\begin{array}{l}\text { Inpatient } \\
\text { pharmacists }\end{array}$ & $\begin{array}{l}\text { General } \\
\text { practitioner, } \\
\text { community } \\
\text { pharmacist }\end{array}$ & $\begin{array}{l}\text { Asynchronous, } \\
\text { bidirectional } \\
\text { General practitioner/ } \\
\text { community } \\
\text { pharmacists } \\
\leftrightarrow \text { Inpatient } \\
\text { pharmacists }\end{array}$ & $\begin{array}{l}\text { Inpatient pharmacists } \\
\text { called general } \\
\text { practitioner and } \\
\text { community pharmacists; } \\
\text { community pharmacists } \\
\text { returned the confirmed } \\
\text { medication list via fax }\end{array}$ & Not reported \\
\hline Stowasser $2002 b$ & $\begin{array}{l}\text { Resident medical } \\
\text { officers }\end{array}$ & $\begin{array}{l}\text { General } \\
\text { practitioner }\end{array}$ & Not reported & Not reported & Not reported \\
\hline Harris 2001 & ED provider & $\begin{array}{l}\text { General } \\
\text { practitioner }\end{array}$ & $\begin{array}{l}\text { Asynchronous, } \\
\text { bidirectional } \\
\text { General practitioners } \\
\leftrightarrow \text { ED providers }\end{array}$ & $\begin{array}{l}\text { Written letter taken } \\
\text { in-person by patient, } \\
\text { faxed or mailed in to } \\
\text { the ED }\end{array}$ & Not reported \\
\hline Ramrakha 2001 & ED provider & $\begin{array}{l}\text { General } \\
\text { practitioner }\end{array}$ & $\begin{array}{l}\text { Unidirectional } \\
\text { General practitioners } \\
\quad \rightarrow \text { ED providers }\end{array}$ & $\begin{array}{l}\text { Referral letters sent in with } \\
\text { patients; some general } \\
\text { practitioners also called in } \\
\text { directly to ED }\end{array}$ & Not reported \\
\hline
\end{tabular}


Table 2. (continued)

\begin{tabular}{|c|c|c|c|c|c|}
\hline Author, Year & $\begin{array}{l}\text { Acute Care } \\
\text { Provider(s) } \\
\text { Involved in } \\
\text { Communication }\end{array}$ & $\begin{array}{l}\text { Outpatient } \\
\text { Provider(s) } \\
\text { Involved in } \\
\text { Communication }\end{array}$ & $\begin{array}{l}\text { Direction of } \\
\text { Communication }\end{array}$ & $\begin{array}{l}\text { Mode(s) of } \\
\text { Communication }\end{array}$ & $\begin{array}{l}\text { Frequency of } \\
\text { Communication }\end{array}$ \\
\hline Mead 1999 & $\begin{array}{r}\text { Admitting } \\
\text { doctors }\end{array}$ & $\begin{array}{l}\text { General } \\
\quad \text { practitioner }\end{array}$ & $\begin{array}{l}\text { Unidirectional } \\
\text { General practitioners } \\
\rightarrow \text { admitting } \\
\text { doctors }\end{array}$ & $\begin{array}{l}\text { Hand-written or type- } \\
\text { written letters sent in } \\
\text { with patients }\end{array}$ & Not reported \\
\hline Ways 1995 & $\begin{array}{l}\text { Medical } \\
\quad \text { residents }\end{array}$ & $\begin{array}{c}\text { Primary care } \\
\text { provider }\end{array}$ & $\begin{array}{l}\text { Synchronous, } \\
\text { bidirectional } \\
\text { Primary care } \\
\text { providers } \\
\leftrightarrow \text { Ward team } \\
\text { member }\end{array}$ & $\begin{array}{l}\text { PCPs were contacted } \\
\text { by a ward team } \\
\text { member by telephone } \\
\text { message or live call }\end{array}$ & $\begin{array}{l}\text { Of } 105 \text { patients who } \\
\text { reported having a } \\
\text { primary care provider } \\
\text { at a single hospital, } 74 \\
\text { providers }(70.5 \%) \\
\text { were contacted }\end{array}$ \\
\hline Montalto 1994 & ED provider & $\begin{array}{l}\text { General } \\
\text { practitioner }\end{array}$ & $\begin{array}{l}\text { Unidirectional } \\
\text { General practitioners } \\
\rightarrow \text { ED providers }\end{array}$ & $\begin{array}{l}\text { Referral letters sent in } \\
\text { with patients }\end{array}$ & $\begin{array}{l}\text { Of } 3223 \text { patients who } \\
\text { presented to the ED, } \\
635(19.7 \%) \text { had } \\
\text { referral letters from } \\
\text { their general } \\
\text { practitioners }\end{array}$ \\
\hline Victor 1993 & House officer & $\begin{array}{l}\text { General } \\
\text { practitioner }\end{array}$ & Not reported & Not reported & Not reported \\
\hline
\end{tabular}

${ }^{I}$ Predominantly unidirectional, although $5.8 \%$ of communication occurred by telephone (i.e., was bidirectional)

${ }^{i i}$ Predominantly unidirectional, although $8 \%$ also called the ED directly (i.e., was bidirectional)

$E D=$ emergency department; $P C P=$ primary care provider

One additional study reported communication between the nursing home staff and the emergency department staff. Though this study did not exclusively report direct communication between providers, it did include their assessment of the provider-to-provider communication from the nursing home to emergency department setting; thus, it was included. ${ }^{34}$

Mode of Communication. Among the 14 studies, ${ }^{15,16,21-24,27-}$ ${ }^{34}$ multiple modes of communication were described (Table 2). Providers in five of 14 studies (36\%) communicated with referral letters, either sent in with patients or sent electronical$1 y, 23,30,31,33,34$ four studies (29\%) described providers communicating via telephone calls; ${ }^{24,28,30,32}$ three studies (21\%) involved communication via fax; ${ }^{16,32,33}$ and one study described providers reviewing notes from the medical record to ascertain whether the inpatient provider had documented communication with the primary care provider at admission or not. ${ }^{21}$ The remaining four studies $(29 \%)$ did not explicitly report on the mode of communication, though all noted that successful communication did occur with the outpatient provider. ${ }^{15,22,27,29}$

Directionality of Communication. Among the 14 studies reporting on frequency of communication, four (29\%) involved unidirectional communication ${ }^{23,28,30,31}$ and five (36 \%) reported bidirectional communication ${ }^{16,24,32-34}$ (Table 2). Directionality of the remaining five studies was unclear. $^{15,21,22,27,29}$ An example of unidirectional communication was general practitioners sending in referral letters with patients to be given to the ED provider. ${ }^{31}$ An example of bidirectional communication was an inpatient provider telephoning the primary care provider. ${ }^{24}$ Directionality of communication did not seem to be related to the frequency of communication.

\section{Outcomes}

Only six of 20 studies (30\%) evaluated outcomes associated with provider-to-provider communication. ${ }^{15,21,22,24,29,32,34}$

Three studies evaluated readmissions (see Table 3). Two of those studies noted that the occurrence of communication (direct communication with a primary care provider ${ }^{29}$ and participation in a medication liaison service intervention ${ }^{32}$ ) was associated with non-statistically significant decreases in odds of 30-day readmissions when compared to usual care, and the other study found no association between communication and readmissions (OR 1.08, $95 \%$ CI 0.92-1.26). ${ }^{15}$ One of these studies also found non-statistically significant improvements in 30-day mortality and 30-day ED visits with communication (see Table 3). ${ }^{29}$ Stowasser et al. also noted a non-significant decrease in the utilization of community healthcare resources within 30 days of discharge for those who participated in a medication liaison service in which inpatient pharmacists communicated with the general practitioner and community pharmacist about medication reviews compared to the control group, which did not have this communication. ${ }^{32}$

Finally, three studies evaluated patient or provider satisfaction. Stowasser et al. ${ }^{22}$ and Zamora et al. ${ }^{34}$ both found that providers reported high satisfaction with interventions to promote direct provider-to-provider communication. Hruby et al.'s ${ }^{21}$ study of patient satisfaction reported that $90 \%$ of 
Table 3 Association Between Communication and Health Care Utilization $(n=3)$

\begin{tabular}{ll}
\hline \hline Study, Year & Communication and Health Care Utilization \\
\hline Oduyebo 2013 & 30-day readmissions: \\
& Successful vs. unsuccessful communication: \\
& 2438/6635 (36.7 \%) vs. 4197/6635 (63.3\%); \\
& adjusted OR 1.08 (95\% CI 0.92-1.26)
\end{tabular}

Bell 2008

$$
\begin{aligned}
& \text { 30-day readmissions: } \\
& \text { Direct vs. no communication: 22/194 (11.2\%) } \\
& \text { vs. 79/640 (12.4 \%); crude OR } 0.91 \\
& \text { (95\% CI 0.55-1.50) } \\
& \text { 30-day mortality: } \\
& \text { Direct vs. no communication: } 14 / 194(7.4 \%) \\
& \text { vs. no communication 54/640 (8.3\%); crude } \\
& \text { OR 0.84 ( } 95 \% \text { CI 0.46-1.56) } \\
& \text { 30-Day ED visit: } \\
& \text { Direct vs. no communication: } 11 / 194(5.5 \%) \\
& \text { vs. 56/640 (8.8 \%); crude OR } 0.63(95 \% \mathrm{CI} \\
& 0.32-1.22)
\end{aligned}
$$

Stowasser 2002a 30-day readmissions:

Medication Liaison Services intervention vs. control:

$12 / 133(11 \%)$ vs. $17 / 127(13 \%)$

Crude OR 0.77 (95\% CI 0.35-1.69)

Subjects undergoing $\geq 1$ unplanned readmissions:

Medication Liaison Services intervention vs. control: $9 / 113(8 \%)$ vs. $12 / 127$ (9.4\%); crude OR 0.59 (95\% CI $0.25-1.37)$

patients surveyed noted that they were satisfied with the communication between the inpatient team and their primary care provider.

\section{Risk of Bias}

As the majority of studies were observational, we utilized 13 of the most relevant questions from the Downs and Black risk of bias tool (see Appendix C online). ${ }^{14}$ The majority of studies were noted to have high risk of bias. Figure 2 highlights five of the 13 quality items evaluated. The full results of the risk of bias are shown in the online supplement.

\section{DISCUSSION}

We found few studies evaluating provider-to-provider communication at the transition from outpatient to acute care, and the majority of these were cross-sectional. The frequency of communication ranged widely across the studies reporting on this, and few studies reported on either clinical or satisfaction outcomes. The majority of the communication between outpatient and acute care providers consisted of primary care providers and general practitioners communicating with inpatient medical providers (hospitalists, admitting doctors, medical residents). Bidirectional communication was slightly more common than unidirectional communication (36 \% vs. $29 \%$, respectively), but it was often unclear who was initiating bidirectional communication. The highest rate of communication was via telephone calls. The advantage of this mode is that it allows for synchronous bidirectional communication between providers, decreasing chances of miscommunication. The main disadvantage is successfully reaching the intended providers in a timely manner. If direct communication can

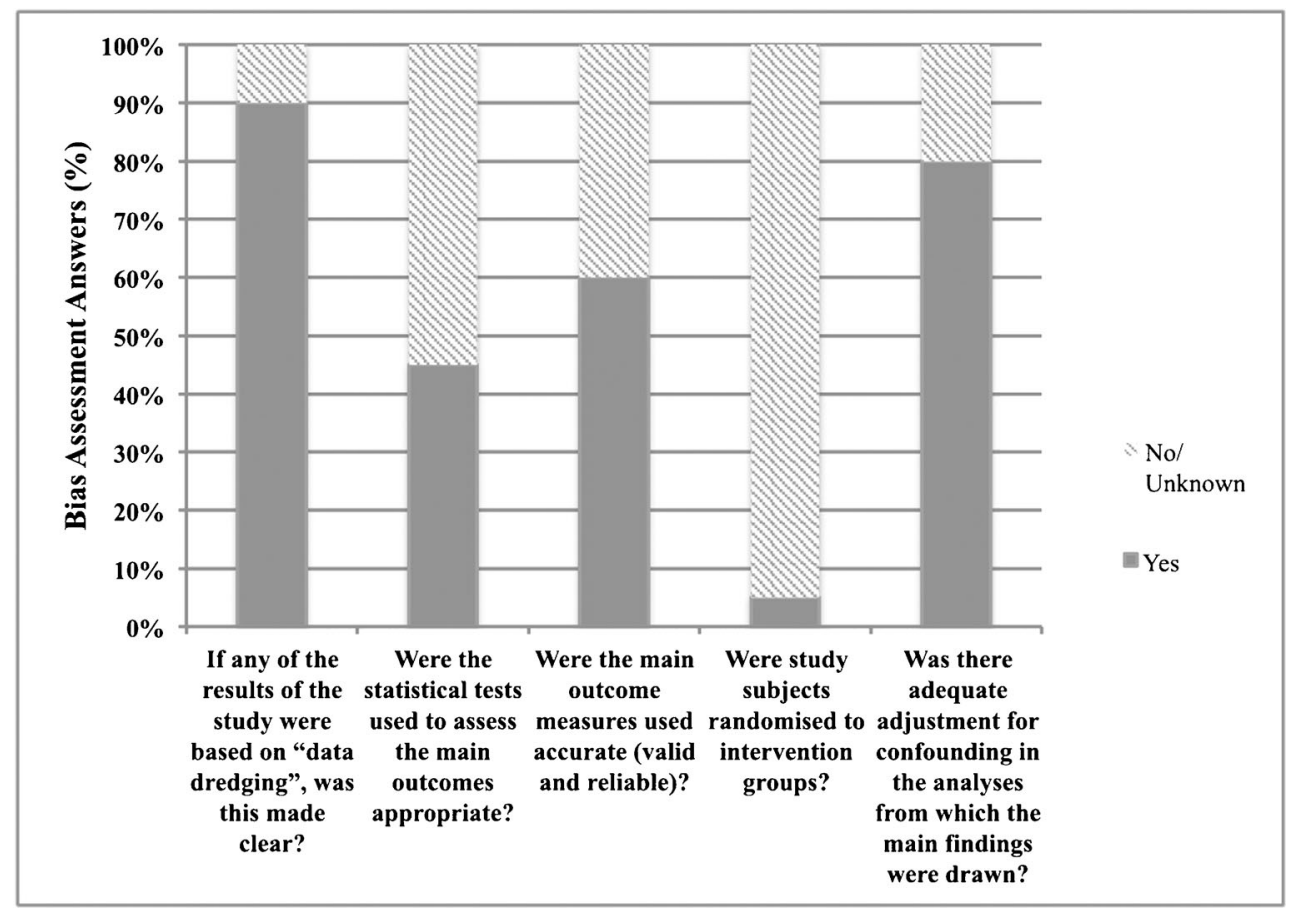

*Modified from Downs SH, Black N. The feasibility of creating a checklist for the assessment of the methodological quality bothof randomised and non-randomised studies of health care interventions. J EpiComHealth.1998;52(6):377-384.

Figure 2 Risk of bias assessment selected results $(n=20)$ 
improve the inbound outpatient to acute care transition, then future interventions/policies should explore ways to incentivize providers on both sides of the transition to prioritize this mode. The second most frequent mode was via referral letters. Interestingly, referral letters were only done in Australia and the United Kingdom, ${ }^{23,30,31,33}$ and none were done in the United States.

While most (five of six) studies reporting on outcomes (30day readmissions, mortality, ED visits, resource utilization, patient and provider satisfaction) observed better outcomes with successful communication, none of the findings were statistically significant $(p<0.05)$. Notably, these studies may have been underpowered for these outcomes, given their sample size, event rates, and frequency of communication.

Provider-to-provider communication is important to mitigate the information gap that commonly occurs when patientrelated information is not available to the provider at point of care. One study ${ }^{35}$ noted that one-third of visits to their emergency department had information gaps. This information gap could be addressed through consistent provider-to-provider communication.

Our findings on the transition from the outpatient to acute care setting complement those found for the inpatient to outpatient transition for which there is an extensive literature. Kripalani et al. ${ }^{5}$ noted the substantial deficits in communication between providers at times of discharge. ${ }^{5}$ Discontinuity in the transition from inpatient to outpatient care has been shown to lead to medical errors and patient safety concerns, ranging from lab and radiology results pending on hospital discharge ${ }^{36}$ to adverse drug reactions ${ }^{37}$ to readmissions. ${ }^{10}$ Moreover, Hesselink et al., ${ }^{38}$ in their review of patient handovers from hospital back to primary care, concluded that multicomponent interventions were most effective. The effective interventions usually included careful medication review, use of electronic health records to transfer information to the primary care provider, provider access to electronic discharge information, and shared involvement between the hospital and outpatient providers. ${ }^{38}$ Awareness on both the acute care and outpatient providers of the need for communication at these critical junctures of transitions is key.

The major limitation to this systematic review is a lack of high-quality studies evaluating provider-to-provider communication during the transition from the outpatient to acute care setting. Heterogeneity of the studies also limited our ability to quantitatively synthesize results. We excluded non-English language articles, limiting the generalizability of our findings to non-English-speaking countries that may have different approaches to provider-to-provider communication based on culture and infrastructure when compared to the countries where our articles were derived. For example, though the French health system also has universal coverage like Australia and the United Kingdom, they currently have two different electronic health systems, one that provides information on hospital admissions and the other on outpatient and hospital claims. On the other hand, the Danish health system has a sophisticated electronic medical system in which all general practitioners have access to the discharge letters and can place electronic referrals. ${ }^{39}$

To our knowledge, this is the first systematic review to study provider-to-provider communication during the transition from the outpatient to acute care setting. We found that the literature on this transition is sparse and heterogeneous, and consists of low-quality studies that are not conclusive. Given the established importance of communication at the time of the transition from the acute care to outpatient setting, ${ }^{11}$ the best ways for this communication to occur during the transition from outpatient to acute care setting (e.g., roles and responsibilities, modes of communication) need to be established. In particular, future studies should determine which communication interventions improve important outcomes such as mortality, morbidity, length of stay and costs. Overall, the evidence on providerto-provider communication at the transition from the outpatient to acute care setting is insufficient, and is an area of great potential for improving patient care.

Contributors: None.

Funders: NHLBI Training Grant (5T32HLOO7180-38) to Dr. Luu.

Corresponding Author: Ngoc-Phuong Luu, MD, MHS; Johns Hopkins University School of Medicine, Baltimore, MD, USA (e-mail: nluu3@jhmi.edu).

\section{Compliance with Ethical Standards:}

Prior Presentations: Society of General Internal Medicine Annual Meeting, Toronto, Ontario, Canada, 22-25 April 2015.

Conflict of Interest: The authors declare that they do not have a conflict of interest.

\section{REFERENCES}

1. The Joint Commission. Transitions of Care Portal 2015. Available at: http://www.jointcommission.org/toc.aspx. Accessed 12 Sept 2015.

2. Center for Medicare and Medicaid Services. Transitions of Care Summary 2014. Available at: http://www.cms.gov/Regulations-and-Guidance/Legislation/EHRIncentivePrograms/downloads/8_Transition_of_Care_Summary.pdf. Accessed 12 Sept 2015.

3. Wachter RM, Goldman L. The emerging role of "hospitalists" in the American health care system. NEJM. 1996;335(7):514-517.

4. Pham HH, Grossman JM, Cohen G, Bodenheimer T. Hospitalists and care transitions: the divorce of inpatient and outpatient care. Health Aff. 2008;27(5):1315-1327.

5. Kripalani S, LeFevre F, Phillips CO, Williams MV, Basaviah P, Baker DW. Deficits in communication and information transfer between hospitalbased and primary care physicians: implications for patient safety and continuity of care. JAMA. 2007;297(8):831-841.

6. Coleman EA, Parry C, Chalmers S, Min SJ. The care transitions intervention: results of a randomized controlled trial. Arch Intern Med. 2006; 166(17): 1822-1828.

7. Halasyamani L, Kripalani S, Coleman E, et al. Transition of care for hospitalized elderly patients-development of a discharge checklist for hospitalists. J Hosp Med. 2006; 1(6):354-360.

8. Kripalani S, Jackson AT, Schnipper JL, Coleman EA. Promoting effective transitions of care at hospital discharge: a review of key issues for hospitalists. J Hosp Med. 2007;2(5):314-323.

9. Moore C, Wisnivesky J, Williams S, McGinn T. Medical errors related to discontinuity of care from an inpatient to an outpatient setting. J Gen Intern Med. 2003;18(8):646-651. 
10. van Walraven C, Seth R, Austin PC, Laupacis A. Effect of discharge summary availability during post-discharge visits on hospital readmission. J Gen Intern Med. 2002;17(3):186-192.

11. Snow V, Beck D, Budnitz T, et al. Transitions of Care Consensus policy statement: American College of Physicians, Society of General Internal Medicine, Society of Hospital Medicine, American Geriatrics Society, American College Of Emergency Physicians, and Society for Academic Emergency Medicine. J Hosp Med. 2009;4(6):364-370.

12. Donalson M. Primary care: America's health in a new era. National Academies Press; 1996

13. Woolf B. On estimating the relation between blood group and disease. Ann Human Genet. 1955;19(4):251-253.

14. Downs SH, Black N. The feasibility of creating a checklist for the assessment of the methodological quality both of randomised and nonrandomised studies of health care interventions. J Epi Com Health. 1998;52(6):377-384.

15. Oduyebo I, Lehmann CU, Pollack CE, et al. Association of self-reported hospital discharge handoffs with 30-day readmissions. JAMA Int Med. 2013;173(8):624-629.

16. Hennrikus E. Communication Between the Primary Care Physician and the Hospitalist at the Time of Patient Admission. JCOM.October 2012 2012;19(10):454-456.

17. Terrell KM, Miller DK. Strategies to improve care transitions between nursing homes and emergency departments. J Am Med Dir Assoc. 2011;12(8):602-605.

18. Gillespie SM, Gleason $\mathbf{L}$, Karuza J, Shah MN. Health care providers' opinions on communication between nursing homes and emergency departments. J Am Med Dir Assoc. 2010;11(3):204-210.

19. Harlan G, Srivastava R, Harrison L, McBride G, Maloney C. Pediatric hospitalists and primary care providers: a communication needs assessment. J Hosp Med. 2009;4(3): 187-193.

20. Terrell KM, Miller DK. Challenges in transitional care between nursing homes and emergency departments. J Am Med Dir Assoc. 2006;7(8):499505.

21. Hruby M, Pantilat SZ, Lo B. How do patients view the role of the primary care physician in inpatient care? Dis Mon. 2002;48(4):230-238.

22. Stowasser D, Collins DM, Stowasser M. A Randomised Controlled Trial of Medication Liaison Services - Acceptance and Use by Health Professionals. J Pharm Pract Res. 2002;32(3).

23. Mead GE, Cunnington AL, Faulkner S, Russell KJ, Ford MJ. Can general practitioner referral letters for acute medical admissions be improved? Health Bull. 1999;57(4):257-261.

24. Ways M, Umali J, Buchwald D. Frequency and impact of housestaff contact with primary care physicians. J Gen Intern Med. 1995;10(12):688-690.
25. Balla JJ, w. Improving the continuity of care between general practitioners and public hospitals. Med J Aust. 1994;161(5):656-659

26. Hadfield JM, Yates DW, Berry A. The emergency department and the community: a model for improved cooperation. J R Soc Med. 1994;87(11):663-665

27. Victor CR, Young E, Hudson M, Wallace P. Whose responsibility is it anyway? Hospital admission and discharge of older people in an innerLondon District Health Authority. J Adv Nurs. 1993;18(8):1297-1304.

28. McMillan A, Trompeter J, Havrda D, Fox J. Continuity of care between family practice physicians and hospitalist services. J Healthc Qual. 2013;35(1):41-49.

29. Bell CM, Schnipper JL, Auerbach AD, et al. Association of communication between hospital-based physicians and primary care providers with patient outcomes. J Gen Intern Med. 2009;24(3):381-386.

30. Ramrakha S, Giles A. Take a letter ... an audit of GP referrals in south west Sydney. Aust Fam Physician. 2001;30(4):395-398.

31. Montalto $\mathbf{M}$, Harris $\mathbf{P}$, Rosengarten $\mathbf{P}$. Impact of general practitioners referral letters to an emergency department. Aust Fam Physician. 1994;23(7):1320. -1321, 1324-1325, 1328.

32. Stowasser D, Collins DM, Stowasser M. A Randomised Controlled Trial of Medication Liaison Services - Patient Outcomes. J Pharm Pract Res. 2002;32(2).

33. Harris M, Giles A, O'Toole BI. Communication across the divide: A trial of structured communication between general practice and emergency departments. Aust Fam Physician. 2001;31(2):197-200.

34. Zamora Z, McCall B, Patel L, et al. Implementation of a Web-based system to improve the transitional care of older adults. J Nurs Care Qual. 2012;27(2):182-189.

35. Stiell A, Forster AJ, Stiell IG, van Walraven C. Prevalence of information gaps in the emergency department and the effect on patient outcomes. CMAJ. 2003; 169(10):1023-1028.

36. Roy CL, Poon EG, Karson AS, et al. Patient safety concerns arising from test results that return after hospital discharge. Ann Intern Med. 2005; 143(2): 121-128.

37. Forster AJ, Murff HJ, Peterson JF, Gandhi TK, Bates DW. Adverse drug events occurring following hospital discharge. J Gen Intern Med. 2005;20(4):317-323.

38. Hesselink G, Schoonhoven L, Barach P, et al. Improving patient handovers from hospital to primary care: a systematic review. Ann Intern Med. 2012;157(6):417-428.

39. The Commonwealth Fund. International Profiles of Healthcare Systems, 2012. http://www.commonwealthfund.org/ /media/Files/Publications/ Fund\%20Report/2012/Nov/1645_Squires_intl_profiles_hlt_care_systems_2012.pdf. Accessed: 12, Sept 2015. 